\title{
North Atlantic Crustal Genesis in the Vicinity of the Azores Islands
}

\author{
D.C. KRAUSE \\ Graduate School of Oceanography, University of Rhode Island, Kingston, Rhode Island 02884 \\ and \\ N.D. WATKINS \\ Department of Geology, Florida State University, Tallahassee, Florida 32306 \\ (Received January 12, 1970)
}

\begin{abstract}
In terms of current knowledge of crustal genesis in the Atlantic Ocean, several unique or highly anomalous features exist in the vicinity of the Azores Islands: the seismically active East Azores Fracture Zone extending from Gibralter to the Mid-Atlantic Ridge; the seismically inactive West Azores Fracture Zone which is offset northwards from the trend of the East Azores Fracture Zone; the transverse island chain of the Azores islands which trend southeast-northwest across the Mid-Atlantic Ridge; the marked change in direction of the Mid-Atlantic Ridge from northeast-southwest to north-south; the broadening of the Mid-Atlantic Ridge to the east; and a proposed equatorward decrease of crustal spreading rate across the transverse fracture zones.

Bathymetric and magnetic data from surveys of the Mid-Atlantic Ridge in the Azores area by R.V. Trident, and the U.S. Naval Oceanographic Office have been compiled. These, together with the previously published data are compatible with a crustal genesis model consisting of a Mid-Atlantic Ridge migrating eastwards at the local crustal spreading rate, which is greater to the north than to south of an east-west transverse fracture system. Superimposed on this is the development of a northwest-southeast trending secondary spreading center or triple junction, within a 'leaky transform' system (Menard and Atwater, 1968) which developed as the result of a change in local crustal spreading direction south of the east-west transverse fracture system, from east-west to northwest-southeast. Simple geometrical considerations when combined with the length of a newly proposed 'Azores Rift' and an independently determined crustal spreading rate, suggest that the proposed local change in crustal spreading direction and triple junction development began more than 40 m.y. ago.
\end{abstract}

